\title{
STUDY OF AN ALTERNATE MANUFACTURING PROCESS OF PISTON PIN
}

\author{
Hemant V Chavan ${ }^{1}$, Milind S.Yadav ${ }^{2}$ \\ ${ }^{1}$ Asst Professor, Mechanical Engineering Department, FAMT, Mumbai University, Maharashtra, India \\ ${ }^{2}$ Associatet Professor, Mechanical Engineering Department, FAMT, Mumbai University, Maharashtra, India
}

\begin{abstract}
In automobile industry development in technology has been increases significantly and so as the performance of an engine. In reciprocating internal combustion engine major parts having sliding motion among their parts and failure of any part in dynamic stage will cause major impact on engine such as failure of an engine. Piston pin play a vital role in the reciprocating internal combustion engine. Failure of piston pin will result in failure of engine. It has been investigated that fatigue failureis one of the major reason of failure of a piston pin. Piston pin are subjected to multiaxial stresses due to which crack initiation and propagation from the surface decreases intensely the fatigue strength of surface and fatigue fracture occurredso every effort has to be made towards improvement in sliding properties of piston pin which will reduce wear resistance of metal surface and ultimately increases fatigue life of piston pin without sacrificing any of the major property requirements of the substrate material. Literature shows that phosphating is one of the surface coating method which will improve friction properties and wear properties thus increases fatigue life. In this work, an effort is to suggest phosphate surface coating on a piston pin as an alternative to conventional surface coating. The investigation effect of phosphating surface coating on piston pin of different material is studied by using design of experiments.
\end{abstract}

Key Words: Design of Experiment, Fatigue Strength, Piston pin, Phosphating $* * *$

\section{INTRODUCTION}

In the automotive and machinery industry, there is a great deal of interest in improving environmental friendliness, reliability, durability and efficiency. Developing new technological solutions, such as using of lightweight materials, less harmful fuels, controlled fuel combustion processes or more efficient exhaust gas after-treatment, are possible ways to reduce the environmental impact of vehicles and machines. Major amount energy is lost in engine itself.. Surface coating is one method which can reduce wear and friction thus resulted into reduction in energy loss. Among protective coatings, the class of carbonbased materials shows interesting properties, combining low friction with a good wear resistance. For these reasons, they are increasingly being used as protective films for moving parts such as diesel injection needles, valve train parts, piston pins, tappets or gears .The use of such non-metallic surfaces with new additives leads to investigations into the interaction between these protective over layers and the base material

Y.Q.Liu and et al investigated that stress concentration at upper end of the piston pin is one of the main reason for fatigue failure. Hence design stress is the important parameter affecting the fatigue life of piston pin. [1]

Freeman D.B and et al found the effect of phosphate coating and more specifically manganese phosphate coating on fatigue and wear properties of materials are known to prevent corrosion, prevent welding and reduce friction. He shows that wear on phosphate coated surface increases as the amount of coating on the surface increases and decreases as phosphate grain size increases.[2]

Menke, J.T studied the effect of amount of manganese phosphate coating on surfaces and grain size on fatigue and wear. He shows that wear on phosphate coated surface increases as the amount of coating on the surface increases and decreases as phosphate grain size increases.[3]

\subsection{Problem Definition}

An attempt will be made in the present study to suggest an alternate to DLC coating or to replace super finishing process by phosphating process. Therefore a development of innovative idea to substitute conventional piston pin manufacturing process and to identify the effect of phosphating parameter on fatigue performance of piston pin material Due to its better physical properties it plays a significant role in automobile application like piston and piston ring. With the same mind an effort is made to apply phosphate surface coating to piston pin. Thus problem can be defined as, "Improve fatigue performance of the piston pin by using phosphate surface coating ".

\subsection{Project Scope}

The scope of this project is limited to fatigue life calculation of standard fatigue test specimen with phosphate surface coating which is made of material commonly used for piston pin. This work can be used as a reference for future research on phosphate surface coated piston pin. 


\section{PISTON DAMAGES}

This work is concerned with the causes of piston damages and possibilities of early detection of spark and diesel engine piston failure. During the examinations of faulty working engines, $23 \%$ were connected with faulty pistons, cylinder or valves as shown in figure 1 below.[14]

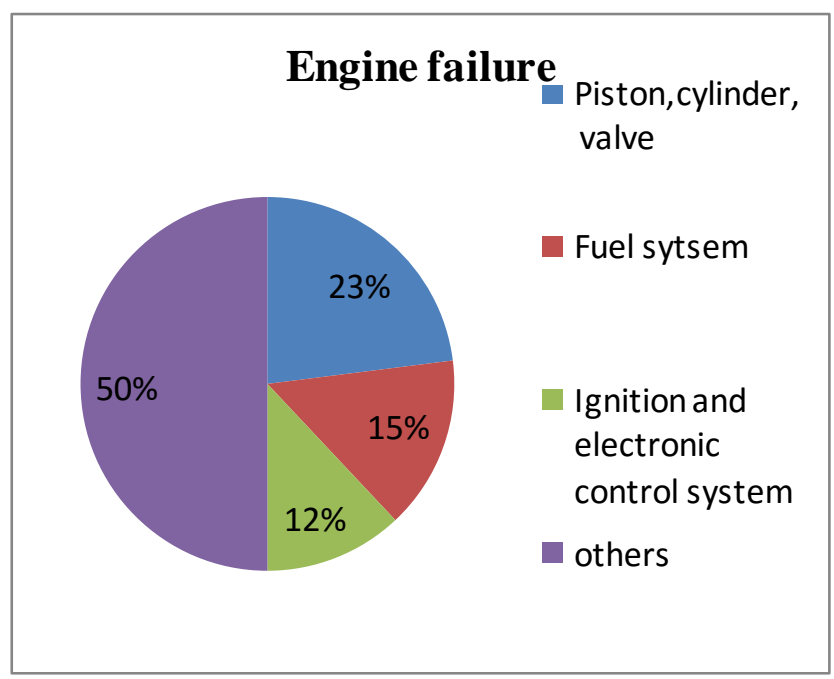

Figure 1. Structure of Engine Faults

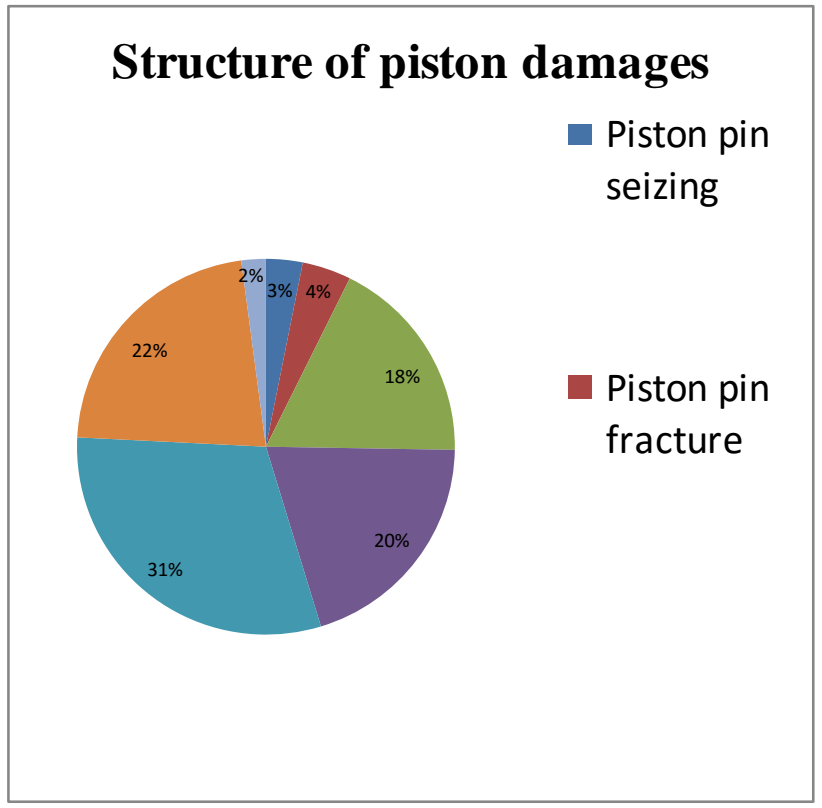

Figure 2. Structures of Piston Damages

The types of piston damages, which have been recognized, can be classified as shown in figure in 2.All these causes result during operational phase.[14]

\subsection{Piston Pin Manufacturing Process}

Carburizing process is identified as one of the bottlenecks in the piston pin manufacturing .Carburizing is the only process which improves wear resistance and hence fatigue life. As the pin is locating in small end of connecting rod which needs to carry a large amount of combustion forces which may result in seizing of piston pin inside small end of connecting rod and this may be lack of lubrication on that end. So to improve better ability of sliding surface coating was proven the best. So emergence of Diamond like Coating or superfinishing process. Both methods provides low sliding friction coefficient with high hardness and wear resistance. It is investigated that diamond like carbon coating is focuses on effects and interaction with of lubricants [12][13]

When a material is deposited, onto a surface of an existing or another material (substrate) it is known as a coating. To improve surface properties of a bulk material is the aim of this coating. Coatings are formed using a mechanical bond between particle splats and the substrate.

\section{CHEMICAL CONVERSION COATING}

Chemical conversion coatings avoids bare metal to metal contact and promotes its application during break in period where the chances of failure is more..The most common types are phosphates, sulfides, and oxides. In chemical conversion coating base metal is converted into protective film which neutralize corrosion effects.Immersion process is the most effective process of coating and covers whole area of component.

\subsection{Phosphating:}

Phosphating process can be defined as the treatment of a metal surface so as to give a reasonably hard, electrically non-conducting surface coating of insoluble phosphate which is contiguous and highly adherent to the underlying metal and is considerably more absorptive than the metal.

\subsection{Phosphate Process Details:}

In general, phosphating sequence comprises of seven operations, as indicated in the flow chart figure

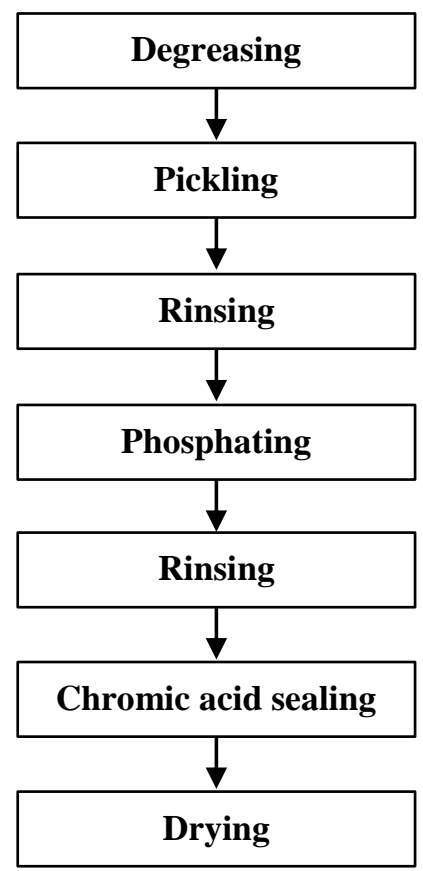

Fig. 3. Operating sequence involved in phosphating process 


\section{METHODOLOGY}

In view of extensive applications of low alloy steel for making automotive component, two different type of material which are commonly used selected for the present study.The chemical composition of each grade of steel was evaluated through the spectroscopic analysis, the result of which are given in table 1 . The most common material for piston pins in general is Low alloy steel steel of grade EN19, EN24 which provide wide range of mechanical properties.

Table 1. Chemcial composition of base material

\begin{tabular}{|c|c|c|}
\hline Element & \% weight EN 19 & \% weight EN 24 \\
\hline $\mathrm{C}$ & 0.41 & 0.47 \\
\hline $\mathrm{Mn}$ & 0.61 & 0.59 \\
\hline $\mathrm{Si}$ & 0.26 & 0.24 \\
\hline $\mathrm{S}$ & 0.023 & 0.022 \\
\hline $\mathrm{P}$ & 0.032 & 0.034 \\
\hline $\mathrm{Cr}$ & 0.920 & 1.1 \\
\hline $\mathrm{Ni}$ & 0 & 1.430 \\
\hline $\mathrm{Mo}$ & 0.270 & 0.250 \\
\hline
\end{tabular}

\subsection{Specimen Preparation For Fatigue Test}

\section{Specimen:}

Based on the recommendations provided in standards, dumbbell shaped round test specimens having nominal neck specimens were prepared for carrying out fatigue tests. The drawing of the specimen is given in figure

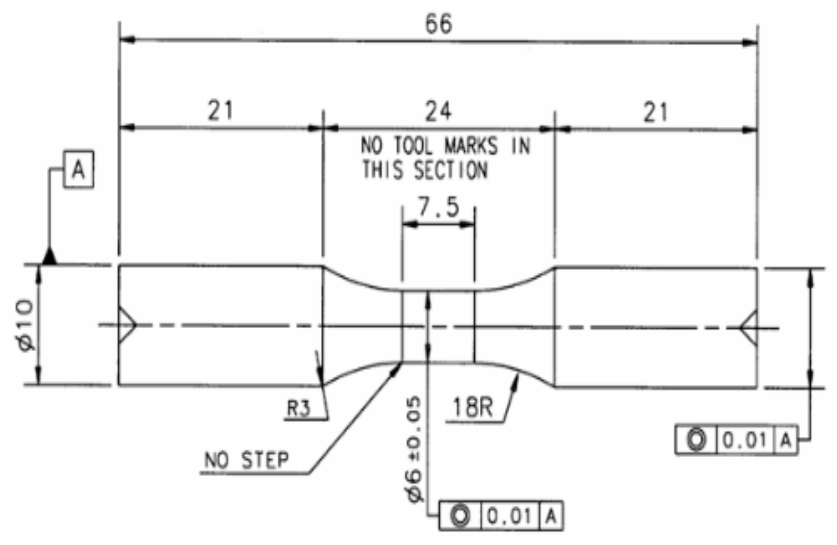

Figure 4 - Drawing Fatigue Test SpecimeN

\section{DESIGN OF EXPERIMENT}

In the present case degree of freedom is two.It is important to notice that the number of experimental trial in the OAs must be greater than the total dof required for studying the effects. Hence $\mathrm{L}_{9} \mathrm{OA}$, requiring nine experimental trials is suitably chosen for the present case in table 3
Table 1. L9 orthogonal array

\begin{tabular}{|c|c|c|c|}
\hline Trials & Temperature & $\begin{array}{c}\text { Phosphating } \\
\text { time }\end{array}$ & Accelerator \\
\hline 1 & 92 & 5 & 1 \\
\hline 2 & 92 & 10 & 1.5 \\
\hline 3 & 92 & 15 & 2 \\
\hline 4 & 93.5 & 5 & 1.5 \\
\hline 5 & 93.5 & 10 & 2 \\
\hline 6 & 93.5 & 15 & 1 \\
\hline 7 & 95 & 5 & 2 \\
\hline 8 & 95 & 10 & 1 \\
\hline 9 & 95 & 15 & 1.5 \\
\hline
\end{tabular}

The three factors temperature, phosphate time, accelerator were considered as the control factors affecting the fatigue life. It is studied that the testing parameters such as temperature, phosphating time and accelerator are easier to control. Hence these three factors are used as the main design factor in the present study

Table 2. Operating parameters and their levels

\begin{tabular}{|c|c|c|c|c|}
\hline \multirow{2}{*}{ Factors } & Unit & \multicolumn{3}{|c|}{ levels } \\
\cline { 3 - 5 } & & 1 & 2 & 3 \\
\hline $\begin{array}{c}\text { Temperature } \\
\begin{array}{c}\text { Phophating } \\
\text { time }\end{array}\end{array}$ & Deg C & 92 & 93.5 & 95 \\
\hline Accelerator & $\mathrm{mL} / \mathrm{L}$ & 1 & 1.5 & 15 \\
\hline
\end{tabular}

\subsection{Response variable}

In the present study, increase in fatigue life of piston pin is the main objective. Hence the response variable is to increase fatigue life of piston pin in number of cycles. Optimum setting of process parameter is a crucial aspect to improve phosphate ability of specimen. The investigation of effects of phosphate coating on fatigue.

The levels are chosen keeping in mind the low thickness of the coating otherwise wear may occur through the coating.life of piston pin material is desirable. Fatigue strength is calculated experimentally for each level of experiment. In the present study $\mathrm{S} / \mathrm{N}$ ratio analysis is done with fatigue life as the performance index and all the calculation are conducted in Minitab 16. As fatigue life is to be maximized, $\mathrm{S} / \mathrm{N}$ ratio is calculated using larger the better criterion and is given by

$$
\frac{S}{N}=-10 \log \left(\frac{1}{r} \sum_{i=1}^{r} \frac{1}{y_{i}^{2}}\right)
$$

Where $\mathrm{y}$ is the observed data and $\mathrm{r}$ is the number of tests in a trial. 
Table 4. Experimental results of improved fatigue life

\begin{tabular}{|c|c|c|c|c|c|}
\hline Trials & Temp & Time & $\begin{array}{c}\text { Accel. } \\
\text { level }\end{array}$ & $\begin{array}{c}\text { Fatigue } \\
\text { life } \\
\text { EN19 }\end{array}$ & $\begin{array}{c}\text { Fatigue } \\
\text { life } \\
\text { EN24 }\end{array}$ \\
\hline 1 & 92 & 5 & 1 & 62703 & 272340 \\
\hline 2 & 92 & 10 & 1.5 & 62819 & 271356 \\
\hline 3 & 92 & 15 & 2 & 62769 & 271437 \\
\hline 4 & 93.5 & 5 & 1.5 & 61995 & 271706 \\
\hline 5 & 93.5 & 10 & 2 & 61883 & 271304 \\
\hline 6 & 93.5 & 15 & 1 & 62533 & 272837 \\
\hline 7 & 95 & 5 & 2 & 62022 & 272565 \\
\hline 8 & 95 & 10 & 1 & 62382 & 272907 \\
\hline 9 & 95 & 15 & 1.5 & 62234 & 272639 \\
\hline
\end{tabular}

\subsection{Main effect plots}

The analysis of the result from the plots, lead to establish the optimal setting levels of process of parameter.

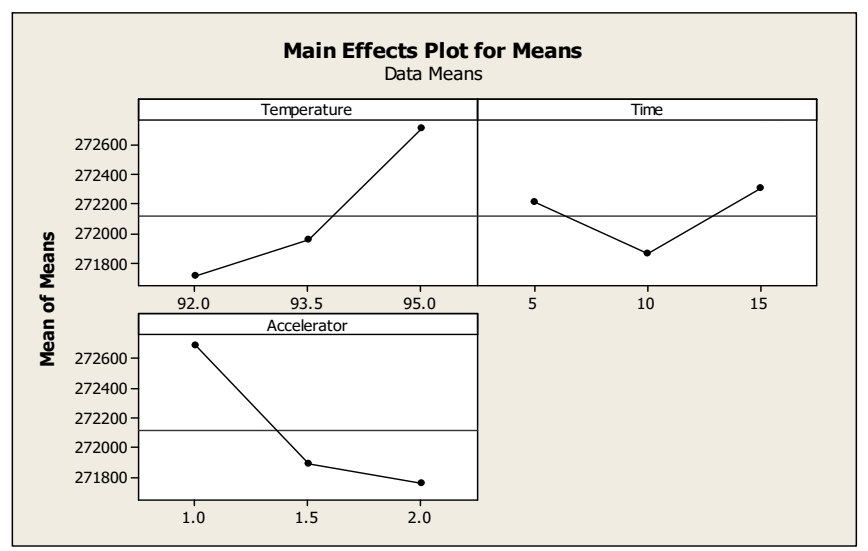

Figure 3. Main effect plot for means EN24

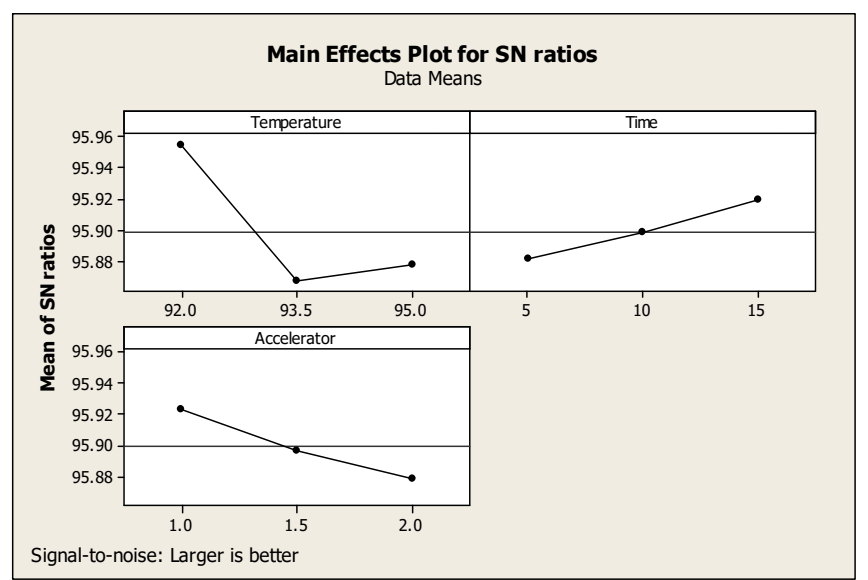

Figure 4. Main effect plot for means EN19

\section{RESULTS AND DISCUSSION .}

1) As it is proved that phosphate coating is generally used for break in purpose because of its porous structure. It is assumed the same application background for the piston pin

2) Phosphate coated piston ring and piston surface have already been used in automobile industry for their respective application, an assumption of the same thermal concept is used for the application of piston pin without any modification.

3) The efficiency of Chemical conversion coating with the purpose of increase of fatigue strength depends on many interconnected factors .

4) The present work is only related with fatigue calculation data of the material which is generally used for piston pin with the help of rotating bending machine by controlling process parameters.

5) The results of experimental investigation also shows that after phosphate coating the fatigue life of steel can be improved within the range of process parameter. Any variation from the range may worsened the results. It is due to the fact that depending on operating temperature of phosphate process, coating of different microstructures can be formed

6) As the phosphate grain is having porous structure which acts as a reservoir for lubricant, it will give much more positive results when operate under lubricated condition.

7) As the phosphating is an immersion process, each material is having different affecting parameter so it is advisable to phosphate one type of material at a time.

\section{CONCLUSIONS}

The experimental results clearly showed that phosphating prolongs fatigue life of piston pin material. The effects have been actually confirmed through the experiments.

Table 5. Comparison of coated with uncoated speciumen

\begin{tabular}{|c|c|c|c|}
\hline $\begin{array}{c}\text { Fatigue } \\
\text { life }\end{array}$ & $\begin{array}{c}\text { Uncoated } \\
\text { life }\end{array}$ & $\begin{array}{c}\text { Coated } \\
\text { life }\end{array}$ & $\begin{array}{c}\% \\
\text { increase in } \\
\text { life }\end{array}$ \\
\hline EN 19 & 50562 & 62638.5 & 19.19 \\
\hline EN 24 & 229786 & 272521.5 & 15.68 \\
\hline
\end{tabular}

\section{ACKNOWLEDGEMENT}

I am especially grateful to Prof. Milind Shashikant Yadav for giving me the opportunity to work under his guidance and for the useful discussions and advice.

I gratefully acknowledge Mr. Darrel Vaz, Owner of Super Engineering Works, Andheri, Mumbai for allowing to work in their factory premises on phosphate coating. 


\section{REFERENCES}

[1] Y.Q.Liu ,Y.X.Wang ,X.H.Men and F.H.Lin "An Investigation On Piston Pin Seat Fatigue Life on The Mechanical Fatigue Experiments", key engineering material, Vol 25, pp.527-531, 2006.

[2] Freeman,D.B, Phosphating and metal pre-treatment: A guide to modern Process and Practice, Industrial Press Inc.(1986)

[3] Menke.J.T. "Process Control For Phosphate Coating" in Products finishing, January 1994

[4] V.Ramamurti,,S.Sridhar,S.mithun, B.kumaravel and S.Lavnya ,IIT madras and WABCO -TVS India ,Chennai ,"Design Consideration Of Piston Pin In Reciprocating Air Compressor By Semi Analytic Approach "Journal of Mechanical Engineering Research, Vol 4(3), pp-75-88,March 2012.

[5]"Fatigue ",chapter 14,elements of metallurgy and engineering Alloys ,ASM international

[6] T.SN Sankara Narayanan, " Surface treatment by phosphate conversion coating ",130-177 ,material science, vol 9, 2006

[7] S.llaiyavel, A.Venkatesan, N.Nallusamy, T.Sornakumar " Wear Characteristics of Manganese Phophate coating with oil lubricant ",616-620 ,applied Mechanics and Materials ,vol 110-116 , 2012.

[8] Sivakumaran llaiyavel, Alankaram Venkatesan " Experimental investigation of Wear Characteristics of Manganese Phophate coated AISI D2 Steel ",518-586 ,International journal of precision engineering and manufacturing, vol $13,2012$.

[9] Zhiwei Yu, Xiaolei Xu, Hongxin Ding " Failure analysis of a diesel engine piston pin.",Engineering failure analysis journal,2005.

[10] W.Rausch,The phosphating of Metals,ASM international Metal Park Finishing Publications,Middlesex, 1990.

[11] S.Ilaiyavel,A.Venkatesan " Investigation of wear coefficient of Manganese phosphate coated tool steel.",Tribology in Industry, Vol 35,69-73,2013.

[12]Arup Gangopadhay, and Kaustav Sinha (2011)," Friction, Wear, and Surface Film Formation Characteristics of Diamond-Like Carbon Thin Coating in Valve train Application", Society of Tribologist and Lubrication Engineers (54) 104-114, 2011.

[13] Sebastien Equey (2004)," Investigation of the Interaction between Diamond-Like Carbon Coatings and Lubricant Additives ", dissertation, Doctor of Sciences.

[14] Jan filipezyk ," Piston Damages-Case Studies and possibilities of Early Detection," Jornal KONES powertrain and Transport,Vol 19,2012.

[15] Vatroslav Grubisic, "Fatigue Failures of Vehicle Components," The Automobile Industry in Japan and Germanyivesin the Age of Globalization Strategic Challenges and New Perspect, Farunhofer,2004.

[16] Sandeep K, ajit Kumar, "Improving Productivity in a Heat Treatment Shop For Piston Pins,"SASTECH journal, Volume 11, Issue 2,Sept 2012.

\section{BIOGRAPHIES}

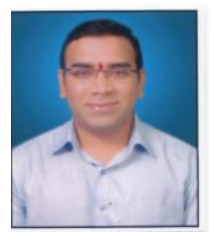

Hemant Vasant Chavan M.E in Mechanical Engg,, FAMT, Mumbai University, Ratnagiri having 08 years experience of teaching.

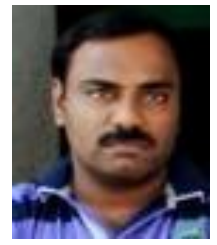

Milind Shashikant Yadav, M.E in Automobile Engg,, Pursuing Ph.D, FAMT Mumbai University, Ratnagiri having 15 years experience of teaching. 